\title{
GP96 is a GARP chaperone and controls regulatory $T$ cell functions
}

\author{
Yongliang Zhang, ${ }^{1}$ Bill X. Wu, ${ }^{1}$ Alessandra Metelli, Jessica E. Thaxton, ${ }^{1}$ Feng Hong, ${ }^{1}$ Saleh Rachidi, ${ }^{1}$ Ephraim Ansa-Addo, ${ }^{1}$ \\ Shaoli Sun, ${ }^{2}$ Chenthamarakshan Vasu, ${ }^{1}$ Yi Yang, ${ }^{1}$ Bei Liu, ${ }^{1}$ and Zihai Li ${ }^{1}$ \\ 'Department of Microbiology and Immunology, Hollings Cancer Center, and ${ }^{2}$ Department of Pathology and Laboratory Medicine, Medical University of South Carolina, Charleston, South Carolina, USA.
}

\begin{abstract}
Molecular chaperones control a multitude of cellular functions via folding chaperone-specific client proteins. CD4 ${ }^{+}$FOXP3 ${ }^{+}$Tregs play key roles in maintaining peripheral tolerance, which is subject to regulation by multiple molecular switches, including mTOR and hypoxia-inducible factor. It is not clear whether GP96 (also known as GRP94), which is a master TLR and integrin chaperone, controls Treg function. Using murine genetic models, we demonstrated that CP96 is required for Treg maintenance and function, as loss of GP96 resulted in instability of the Treg lineage and impairment of suppressive functions in vivo. In the absence of CP96, Tregs were unable to maintain FOXP3 expression levels, resulting in systemic accumulation of pathogenic IFN- $\gamma$-producing and IL-17-producing T cells. We determined that GP96 serves as an essential chaperone for the cell-surface protein glycoprotein A repetitions predominant (GARP), which is a docking receptor for latent membrane-associated TCF- $\beta$ (mLTGF- $\beta$ ). The loss of both GARP and integrins on GP96-deficient Tregs prevented expression of mLTCF- $\beta$ and resulted in inefficient production of active TCF- $\beta$. Our work demonstrates that GP96 regulates multiple facets of Treg biology, thereby placing Treg stability and immunosuppressive functions strategically under the control of a major stress chaperone.
\end{abstract}

\section{Introduction}

Peripheral tolerance to self antigen is critical to ensuring that adaptive immunity is directed specifically against pathogens to avoid autoimmune diseases, which is mediated to a significant degree by Tregs (1-11). Tregs are characterized by their expression of the X-linked forkhead transcription factor FOXP3, which plays essential roles for the establishment and maintenance of Treg identity and suppressive function (12-15). The lineage stability and phenotypic plasticity of Tregs ensure the robustness of tolerance and tissue homeostasis (16). Recent studies have suggested, however, that Tregs may retain lineage plasticity, the ability to switch their cell fate to various $\mathrm{T}$ effector (Teff) cell types, under certain circumstances, such as inflammation (16).

GP96, known also as GRP94 (encoded by HSP90B1), is a paralog of HSP9O in the ER (17). Through genetic and biochemical studies, we demonstrated previously that GP96 is an essential chaperone for folding TLRs, integrins, Wnt coreceptor LRP6, and the platelet glycoprotein Ib/IX/V complex (18-21). GP96 is also required for early $\mathrm{B}$ and $\mathrm{T}$ cell lymphopoiesis (22). These findings suggest that GP96 serve as a specialized immune chaperone that controls receptors for immune function in multicellular organisms. But it is unclear whether GP96 plays any Treg-intrinsic roles in immune tolerance. To answer this question, we undertook a genetic approach to deleting GP96 in a Treg lineage-specific fashion in vivo. We found that GP96 is critically required for multiple aspects of Tregs, including their lineage stability and in vivo-suppressive function. Without GP96, Tregs are unable to maintain adequate FOXP3 expression levels and there is a marked accu-

Conflict of interest: The authors have declared that no conflict of interest exists. Submitted: September 12, 2014; Accepted: December 11, 2014.

Reference information: J Clin Invest. 2015;125(2):859-869. doi:10.1172/JCI79014. mulation of pathogenic IFN- $\gamma$-producing and IL-17-producing T (Th17) cells. It was further unveiled that GP96 chaperones glycoprotein A repetitions predominant (GARP), a cell-surface docking receptor for latent membrane-associated TGF- $\beta$ (mLTGF- $\beta$ ) expressed by Tregs and platelets (23-25). In the absence of GP96, both mLTGF- $\beta$ and the secreted form of active TGF- $\beta$ from Tregs were substantially reduced. Our work thus unmasked a function of GP96 in maintaining immune tolerance and demonstrated that GP96 is an obligate chaperone for GARP in controlling the expression of cell-surface TGF- $\beta$ in vivo.

\section{Results}

Foxp3-Cre-mediated Hsp90b1 deletion in mice causes fatal inflammatory disease. To probe the roles of GP96 in Treg biology in vivo, we genetically deleted GP96 from Tregs by crossing LoxP-flanked GP96 mice $\left(H s p 90 b 1^{f / f}\right)$ with Foxp3-EGFP Cre NOD transgenic mice (26). The Treg-specific GP96 KO (Hsp90b1 $\left.{ }^{A / f} F o x p 3-E G F P^{C r e}\right)$ mice were born at the expected Mendelian ratio without apparent early developmental defect. However, around 4 to 5 weeks after birth, unlike WT (Hsp9Ob1 ${ }^{W T / W T} F o x p 3-E G F P^{\text {Cre }}$ ) or heterozygous (Het, Hsp90b1 ${ }^{f / W T}$ Foxp3-EGFP ${ }^{C r e}$ ) littermates, KO mice began to rapidly lose body weight and succumbed to a severe inflammatory disease (100\% mortality before the age of 100 days) (Figure 1, A and B). Necropsy demonstrated overwhelming infiltrations by mononuclear cells in a variety of organs of all KO mice examined, including the lung, liver, pancreas, and gastrointestinal tract (Figure 1C). Abundant alveolar infiltration was apparent, particularly in the peribronchial and perivascular regions. Liver parenchyma and islets of the pancreas were also heavily infiltrated with mononuclear cells, including neutrophils and lymphocytes, with evidence of organ destruction. There were infiltrations by inflammatory cells in all layers of the gastric mucosa and a striking loss of Paneth cells 
A

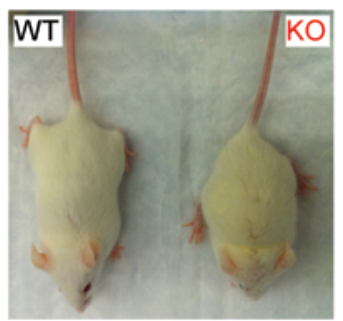

B

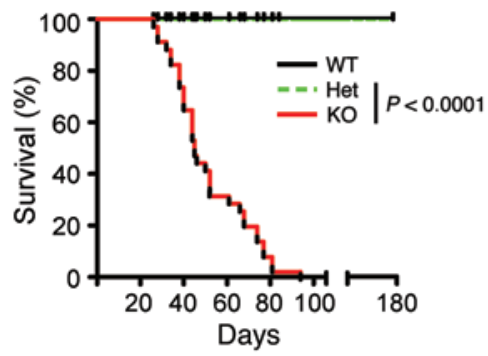

C
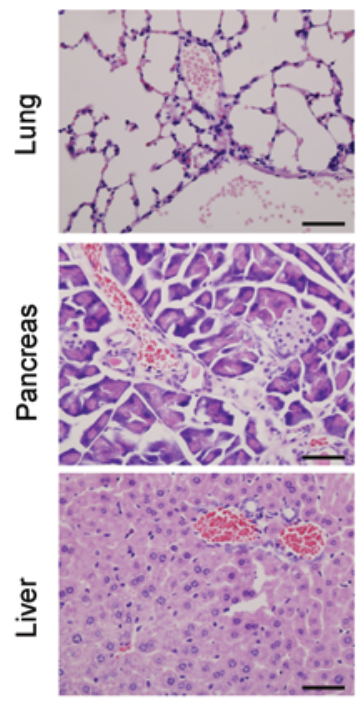
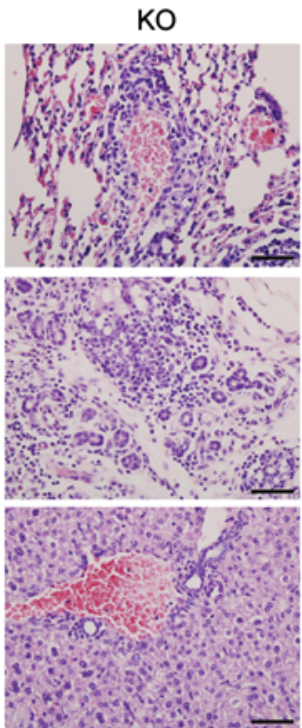

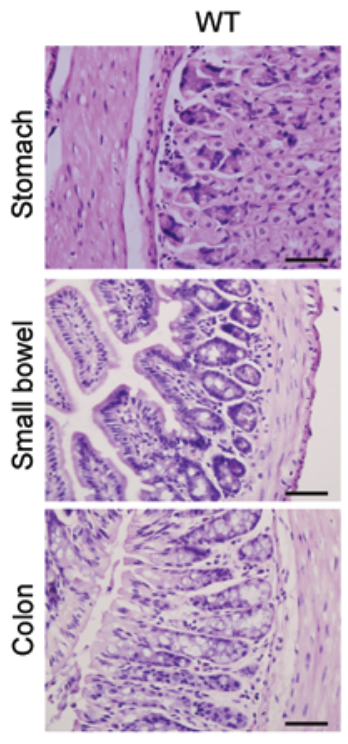

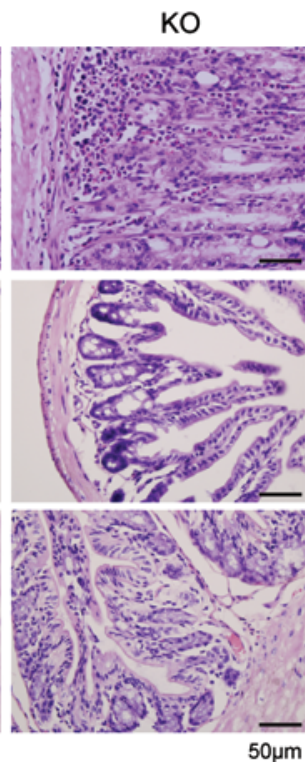

Figure 1. Foxp3-Cre-mediated Hsp90b1 deletion in mice causes a fatal inflammatory disease. (A) Rapid loss of body weight of KO mice (right) compared with WT littermates (left). (B) Survival rate of WT $(n=7)$, Het $(n=10)$, and KO $(n=18)$ mice. Mouse survival data was analyzed by a log-rank (Mantel-Cox) test. (C) H\&E staining of sections of indicated organs from 7-week-old KO mice and WT littermates. Representative results from multiple mice ( $n>3$ ) are shown.

and goblet cells in the small and large intestines, respectively. In addition, $\mathrm{KO}$ mice had significantly higher levels of systemic cytokines including IFN- $\gamma$, IL-2, IL-17, IL-4, TNF- $\alpha$, and IL-6 (Figure $2 \mathrm{~A}$, and Supplemental Figure 1A; supplemental material available online with this article; doi:10.1172/JCI79014DS1), indicating uncontrolled inflammatory $\mathrm{T}$ cell activation. We further characterized the phenotype of FOXP3- ${ }^{-}$cells in the KO mice. Unlike $\mathrm{T}$ cells from WT or Het mice, which were mostly naive, a majority of $\mathrm{T}$ cells from KO mice adopted effector/memory phenotype, with high CD44 and low CD62L expression on the cell surface (Figure 2B and Supplemental Figure 1B). Ex vivo stimulation of these KO T cells with phorbol myristate acetate (PMA) and ionomycin demonstrated a high-level production of IFN- $\gamma$, IL-4, IL-17, and IL-6 (Figure 2C and Supplemental Figure 1C). These striking autoinflammatory diseases and associated broad activation of $\mathrm{T}$ cells were also appreciated in $\mathrm{Cd} 4$ - $\mathrm{Cr}$-mediated GP96 KO mice

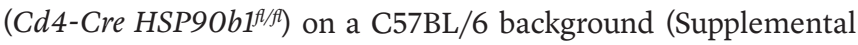
Figure 2). Together, deletion of GP96 from FOXP3 ${ }^{+}$cells led to the development of fatal inflammatory diseases that resemble diseases observed in mice with compromised Treg function, including defects in FOXP3 (2-6) and TGF- $\beta$ (27-30).

GP96-null Tregs develop and persist, but demonstrate compromised suppressive function in vitro. Upon close analysis, we found that Treg number increased significantly in the thymus and spleen of the KO mice, but decreased in lymph nodes (LNs) (Figure 3A and Supplemental Figure 3A). The deletion of GP96 was effective in Tregs, as evidenced by intracellular (IC) stain (Figure 3B). The expansion of $\mathrm{CD}^{+} \mathrm{T}$ cells in the spleen also correlated with reduction of $\mathrm{CD}^{+}$cells and B cells (Supplemental Figure 3B). The difference between the spleen and LNs is most likely due to the fact that GP96-dependent integrins are required for lymphocytes to dwell in the LNs but not in the spleen (31). Indeed, we found that KO Tregs had a defective expression of both integrins and TLRs (Supplemental Figure 3C). More importantly, using loss of cell-surface $\beta_{2}$ integrin as a surrogate, Foxp3-Cre-mediated Hsp90b1 deletion was found to be more efficient in the spleen followed by the LNs and the thymus (Supplemental Figure 3D). By extensive phenotypic analysis, we revealed that KO Tregs had either increased or normal expression of many Treg signature molecules, with reduction of CD62L expression (Figure 3C). Intriguingly, the expression level of FOXP3 itself was consistently decreased in KO Tregs, which correlated with a reduction of cell-surface CD25 (Figure 3D). To examine the homeostatic status of KO Tregs, freshly isolated Tregs from KO mice were stained for cell proliferation marker Ki-67 (Figure 4A) and apoptosis indicator active caspase-3 (Figure 4B). KO Tregs appeared to cycle actively, but were prone to undergoing apoptosis. Moreover, we also performed ex vivo stimulation of $\mathrm{FOXP3}^{+}$cells to determine whether KO Tregs could gain Teff 
A
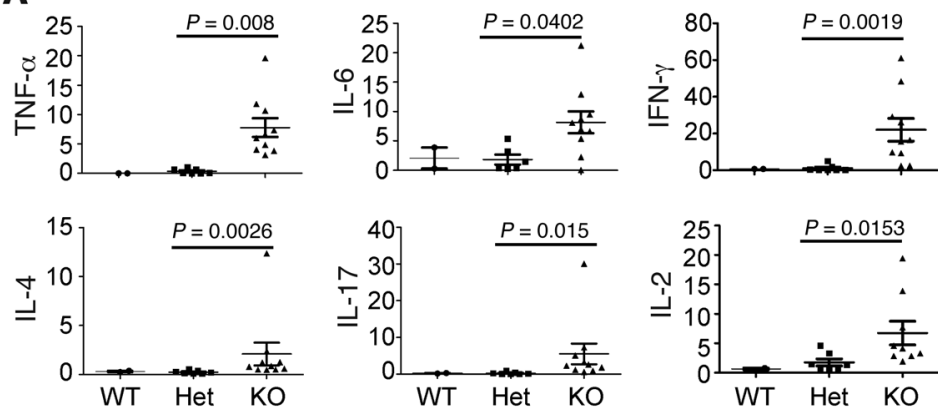

C
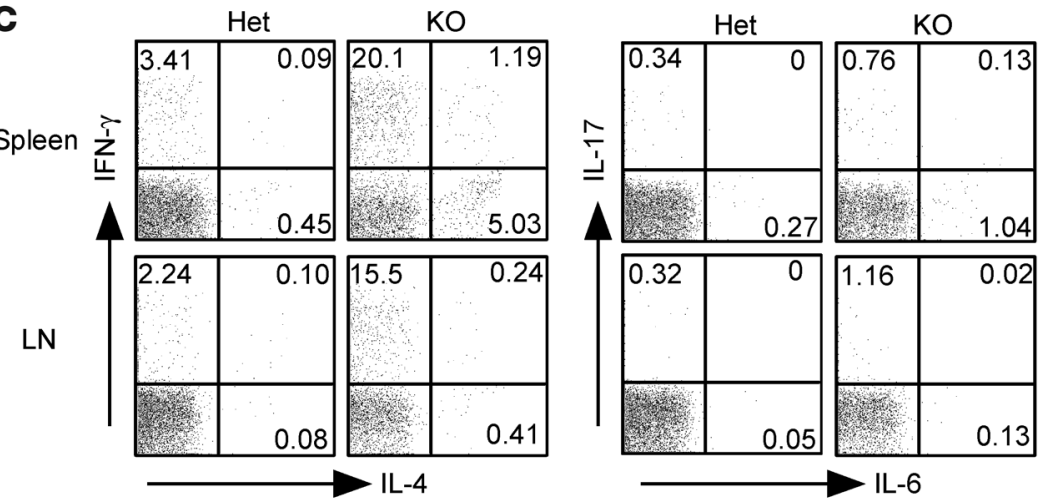

B

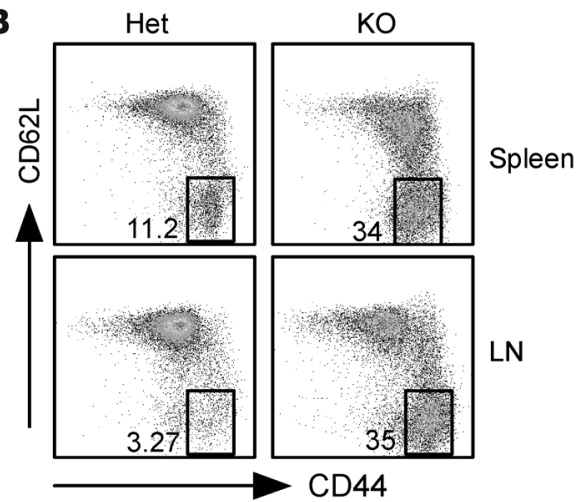

Figure 2. Treg-specific deletion of GP96 in mice triggers systemic cytokine storm and uncontrolled activation of Teff cells. (A) Serum inflammatory cytokine levels (pg/ml) in WT $(n=2)$, NOD Het $(n=6)$, and NOD Foxp3 KO mice $(n=9-10)$. Data are shown as mean \pm SEM. Two-tailed Student's $t$ test was used for comparisons between Het and KO mice. (B) Flow cytometry analysis of CD44 and CD62L expression of CD4+ T cells in 6-week-old KO mice and Het littermates. Numbers indicate percentages of gated cells of all CD4+ cells. (C) Flow cytometry analysis of IC IFN- $\gamma$, IL-4, IL-17, and IL-6 expression by CD4+ T cells from KO mice and Het littermates. Numbers indicate percentages of cells in each quadrant. Representative results from multiple mice are shown.

cell function. Just as with WT Tregs, neither freshly isolated KO Tregs from spleen nor those from LNs produced any appreciable levels of IFN- $\gamma$, IL-2, IL-17, or IL-4 (Supplemental Figure 3E). However, both WT and KO Tregs produced IL-10 (Supplemental Figure $3 \mathrm{~F}$ ). Consistent with the Ki-67 data, we also performed BrdU pulsing analysis and demonstrated that $\mathrm{KO}$ Tregs proliferate more actively (Supplemental Figure 3G).

The heightened proliferation and active phenotypes of Tregs in the $\mathrm{KO}$ mice could be due to a compensatory response to the active inflammation (32). To exclude this potential secondary effect on the expression of Treg signature molecules, we generated mixed BM chimeras by reconstituting sublethally irradiated NOD $\mathrm{Rag}^{-/}$mice with BM cells from CD45.1 KO and CD45.2 WT mice. We observed a similar expression level of many typical Treg markers, including CTLA4, by WT and KO Tregs (Supplemental Figure 3H). Importantly, in vitro suppressive function of GP96null Tregs was significantly compromised, based on a standard suppression assay (Figure 4C).

Failure of GP96 KO Tregs to suppress T cell-mediated autoimmune diseases. We next performed extensive studies to determine the functional competency of GP96 KO Tregs in regulating immune tolerance in vivo. We depleted $\mathrm{CD} 25^{+} \mathrm{T}$ cells from the splenocytes of NOD mice and transferred the remaining diabetogenic splenocytes into NOD $\mathrm{Rag}^{-/}$mice along with purified Tregs from either WT or KO mice. Unlike WT Tregs, KO Tregs were unable to prevent diabetes, as evidenced by hyperglycemia
(Figure 5A), expansion of $\mathrm{T}$ cells with active phenotype (Figure $5, \mathrm{~B}$ and $\mathrm{C}$ ), and insulitis in the recipient mice (Figure 5D). We also assessed the in vivo suppressive function of Tregs in a colitis model. Highly purified $\mathrm{CD} 4{ }^{+} \mathrm{CD} 45 \mathrm{Rb}{ }^{\text {hi }} \mathrm{T}$ cells were transferred into NOD $\mathrm{Rag}^{-/-}$mice along with WT or KO Tregs. Clearly, KO Tregs were unable to prevent colitis (Figure 5, E and F). Finally, we performed a mixed chimera experiment by reconstituting lethally irradiated NOD $\mathrm{Rag}^{-/}$mice with BM cells from WT mice, KO mice, or a 1:1 mixture from WT and KO mice. We found that the loss of tolerogenic function of KO Tregs could be partially rescued by WT hematopoietic cells (Figure 5, G and H).

GP96-null Tregs lose FOXP3 expression and convert to IFN- $\gamma$ producing "ex-FOXP3" $T$ cells. Our observation that KO Tregs express less FOXP3 (Figure 3D) indicates that this lineage is not stable in the absence of GP96. To address this point further, we confirmed the reduced FOXP3 at the protein level by immunoblotting (Figure 6A) and IC stain (Figure 6B) as well as at the mRNA level by a quantitative reverse-transcription PCR (RT-PCR) (Supplemental Figure $4 \mathrm{~A}$ ). Interestingly, about $50 \%$ of $\mathrm{CD}^{+} \mathrm{FOXP}^{-}$ $\mathrm{T}$ cells in the KO mice were "ex-FOXP3" cells, as evidenced by a reduced expression of a GP96 client $-\beta_{2}$ integrin (CD18) (Figure 6C). We reached this conclusion because $H s p 90 b 1$ deletion was accomplished by Foxp3-Cre and because these CD4 ${ }^{+} \mathrm{FOXP}^{-}$ CD18- cells had to express FOXP3 during some points of their ontogeny. To further address the lineage stability of Tregs, we isolated $\mathrm{CD} 4{ }^{+} \mathrm{CD} 25^{+}$natural Tregs from WT or KO mice, followed by 
A

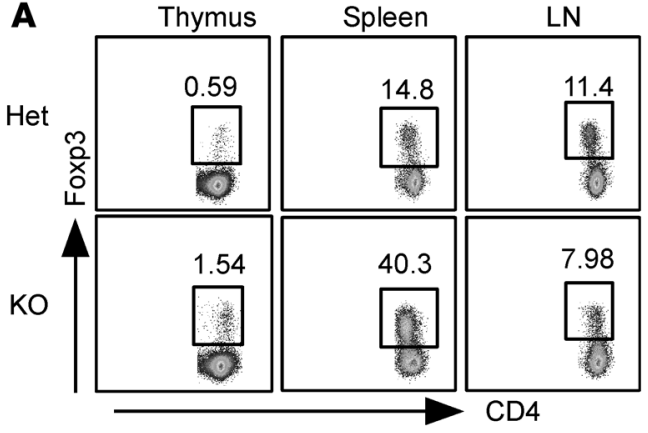

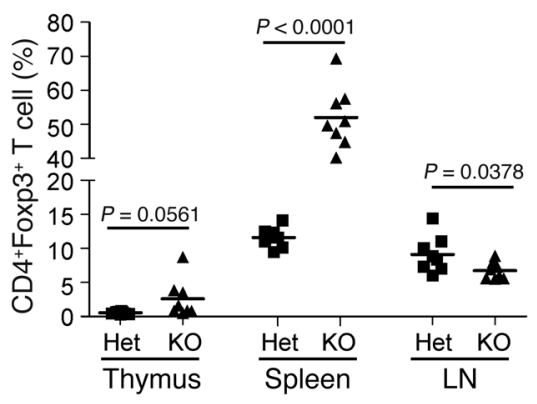

C
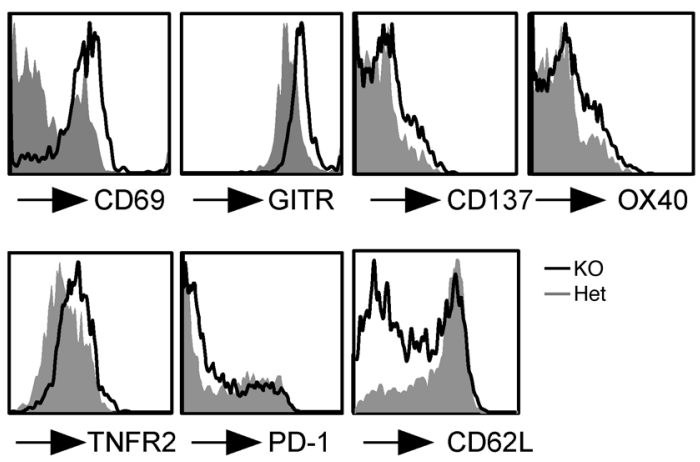

Figure 3. Enumeration and phenotypic characterization of GP96-null Tregs. (A) Enumeration of $\mathrm{CD} 4^{+} \mathrm{FOXP3}^{+}$cells in the thymus, spleen, and LN from 4- to 6-week-old mice by flow cytometry. Numbers indicate percentages of gated $\mathrm{FOXP3}^{+}$ cells of all $C D 4^{+}$cells. $n=8$. (B) IC stain of GP96 from FOXP3 ${ }^{+}$Tregs from the LNs of Het and KO mice. Gray histograms, isotype; open histograms, anti-GP96 antibody. (C) Flow cytometry analysis of cell-surface marker of Tregs from the LNs of KO mice and WT littermates. Shown are representative data from more than 3 independent experiments. (D) Expression of FOXP3 and CD25 in splenic $\mathrm{CD}^{+}{ }^{+} \mathrm{FOXP3} 3^{+}$Tregs from the indicated mice. Shown are representative data from more than 3 independent experiments.

D

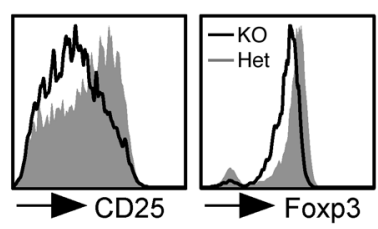

stimulation with plate-bound antibodies against CD3 and CD28 in the presence of IL-12 in vitro. We found that even after stimulation for only 3 days, KO Tregs began to lose FOXP3 and gain expression of IFN- $\gamma$ (Figure 6D). To understand the roles of GP96 in maintaining the stability of Tregs in vivo, highly purified WT or $\mathrm{KO} C D 4^{+} \mathrm{FOXP}_{3} \mathrm{GFP}^{+}$Tregs were adoptively transferred to NOD $\mathrm{Rag}^{-1}$ mice. The fate of these Tregs was then followed over time by staining for FOXP3 and IFN- $\gamma$. We found that WT Tregs were stably maintained. However, KO Tregs progressively lost FOXP3 (Figure 6, E and F) and gained expression of IFN- $\gamma$ (Figure 6, G and H). We conclude that GP96 is indispensable for maintaining Treg lineage stability in vivo.

Recent studies suggest that stable FOXP3 expression correlates well with the DNA demethylation status of the conserved noncoding sequence 2 (CNS2) of the Foxp 3 promoter, particularly in the Treg-specific demethylated region (TSDR) $(33,34)$. We next compared TSDR demethylation status between WT and KO Tregs by real-time PCR (35). It was found that the TSDRs of both WT and KO Tregs were highly demethylated (WT: 79.7\%; KO: $87.6 \%$ ), indicating that loss of FOXP3 stability in the absence of GP96 was not due to TSDR methylation. Interestingly, we did observe that about $43.7 \%$ of Teff cells from KO mice had TSDR demethylation (Supplemental Figure 4B), which correlated precisely with the similar percentage of ex-FOXP3 cells in the total number of Teff cells (Figure 6C). The persistence of TSDR demethylation status in Teff cells provided a further proof for the increased conversion of $\mathrm{FOXP}^{+}$Tregs to IFN- $\gamma$-producing exFOXP3 T cells in the absence of GP96.

GP96 is a critical chaperone for cell-surface expression of GARP and $m L T G F-\beta$. We so far unveiled that GP96 is required for the stability and tolerogenic function of Tregs. Since the phenotype of GP96 KO mice resembles mice with a defect in TGF- $\beta$ biogenesis, maturation, and signaling $(27,28,36-40)$, we decided to look closely at the possibility of GP96 in directly regulating TGF- $\beta$. As a master regulatory cytokine for multiple aspects of Tregs, TGF- $\beta$ exists in at least 3 forms: the soluble and active TGF- $\beta$, latent TGF- $\beta$ associated with latent TGF- $\beta$-binding protein (LTBP), and mLTGF- $\beta$, through its interaction with GARP (also known as LRRC32) (41, 42). Like members of the TLR family, GARP is also a member of the leucine-rich repeat-containing protein family (23, $25,43,44)$. We hypothesized that GARP may also be a client protein of GP96. If so, in the absence of ER chaperone GP96, GARP would not be folded correctly, preventing its exit from the ER and expression at the cell surface. One would then expect to see a concurrent reduction of GARP and mLTGF- $\beta$ on KO Tregs.

WT $\mathrm{FOXP3}^{+} \mathrm{CD}^{+}$cells from the thymus and spleen indeed express both GARP and mLTGF- $\beta$, which is upregulated after 1-day stimulation with antibodies against CD3 and CD28 (Figure 7A). In striking contrast, KO Tregs express substantially less GARP and mLTGF- $\beta$ on the cell surface, which is especially apparent with 
A
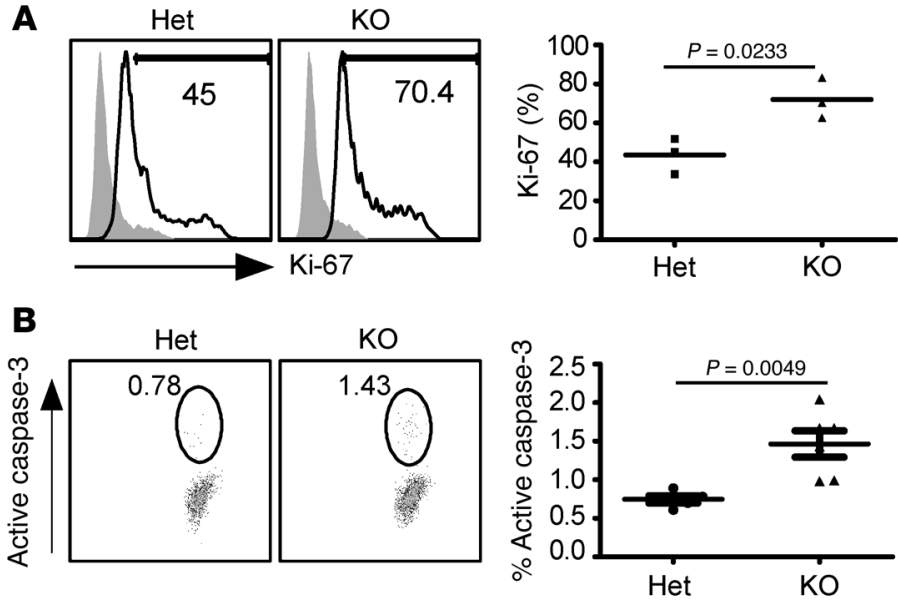

C

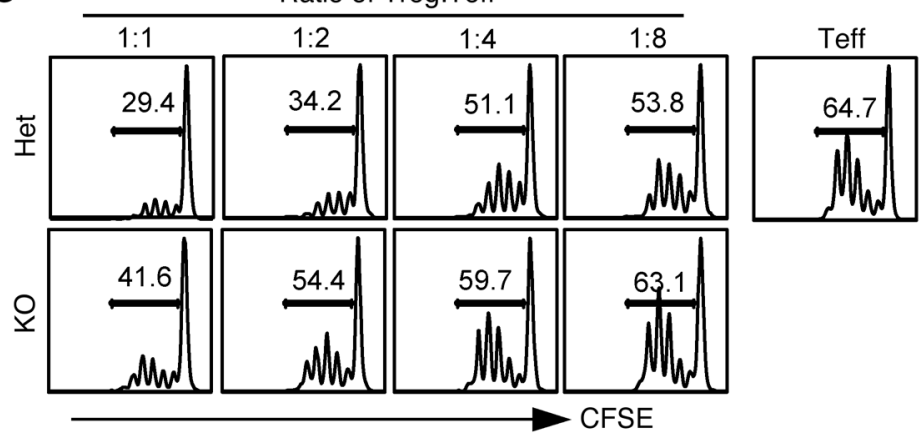

Figure 4. Increased turnover of Tregs and their compromised in vitro suppressive function in the absence of GP96. (A) IC Ki-67 stain of CD4 ${ }^{+}$FOXP3GFP+ Tregs and quantification of the ratio of Ki-67-positive cells in total Tregs. Data are representative of 2 independent experiments. Two-tailed Student's $t$ test was used for comparisons of different experimental groups. (B) Treg apoptosis was assayed by active caspase- 3 staining. Numbers represent percentages of active caspase $-3^{+}$cells among total Tregs. Data are representative of 2 independent experiments. Two-tailed Student's $t$ test was used for comparisons between Het and KO mice. (C) Suppression of proliferation of CFSE-labeled $C D 4^{+} C D 25^{-} T$ cells by splenic $\mathrm{CD} 4^{+} \mathrm{CD} 25^{+} \mathrm{T}$ cells from $\mathrm{KO}$ mice and control littermates. Percentages of CFSE ${ }^{10}$ in the population of all $\mathrm{CD}^{+}$cells are indicated. Five individual experiments were performed with similar findings.

the fact that GP96 also chaperones multiple integrins (Supplemental Figure 3C), which are important for TGF- $\beta$ activation $(22,46,47)$, we hypothesized that GP96 regulates Treg function by controlling TGF- $\beta$ bioactivity. We next performed a series of experiments to determine whether active TGF- $\beta$ production by GP96 KO Tregs is indeed compromised. Using MACS beads, we isolated $\mathrm{CD} 4^{+} \mathrm{CD} 25^{+} \mathrm{T}$ cells from WT and KO mice and stimulated them with platebound antibody against CD3 and CD28. The active TGF- $\beta$ level in the culture supernatant was reduced significantly compared with KO Tregs (Figure 8A). We also examined SMAD2/3 phosphorylation status, which reflects the canonical TGF- $\beta$-signaling pathway. We found that SMAD2/3 were inefficiently phosphorylated in KO Tregs when cells were stimulated with antibodies against CD3 and CD28 for 24 hours, although both WT and KO Tregs responded equally well to exogenous TGF- $\beta$ (Figure 8B). Furthermore, a Th17 cell conversion assay was used to determine the level of active TGF- $\beta$ production by Tregs. Tregs were first stimulated with plate-bound anti-CD3 antibody, followed by irradiation and coculturing with $\mathrm{CD} 4^{+} \mathrm{CD} 25^{-}$naive $\mathrm{T}$ cells, along with IL-6 for 3 days, with or without integrin inhibitor. In this system, the only source of active TGF- $\beta$ was from Tregs, which were reflected indirectly by the conversion of naive T cells to IL-17A-producing T cells. Once again, the KO Tregs demonstrated a lower ability in driving Th17 cell differentiation (Supplemental Figure 5A) and IL-17 production (Figure 8C). The dependence on integrin in this assay was clearly demonstrated by blocking of IL-17 production with an integrin inhibitor, Arg-Gly-Asp (RGD) peptides.

Given that the generation of inducible Tregs (iTregs) is dependent on TGF- $\beta$ activity, we further examined the efficiency of iTreg induction in the absence of GP96. We found that iTregs could not be induced efficiently in vitro without GP96 (Supplemental Figure 5B). Moreover, an in vivo iTreg conversion assay was performed by transferring WT or GP96 KO naive CD25$\mathrm{CD}^{+} \mathrm{T}$ cells into NOD $\mathrm{Rag}^{-/}$mice, followed by an enumeration of donor FOXP3 ${ }^{+}$Tregs in the recipient mice over time. We found that unlike WT naive T cells, KO naive T cells failed to convert to $\mathrm{CD}^{2} 5^{+} \mathrm{FOXP}^{+}{ }^{+}$iTregs (Figure 8, D and E). Finally, we demonstrated that exogenous TGF- $\beta$ given systemically was able to partially rescue the lethal phenotype of $\mathrm{BM}$ recipient mice whose donors were Treg-specific GP96 KO mice (Figure 8F). 
A
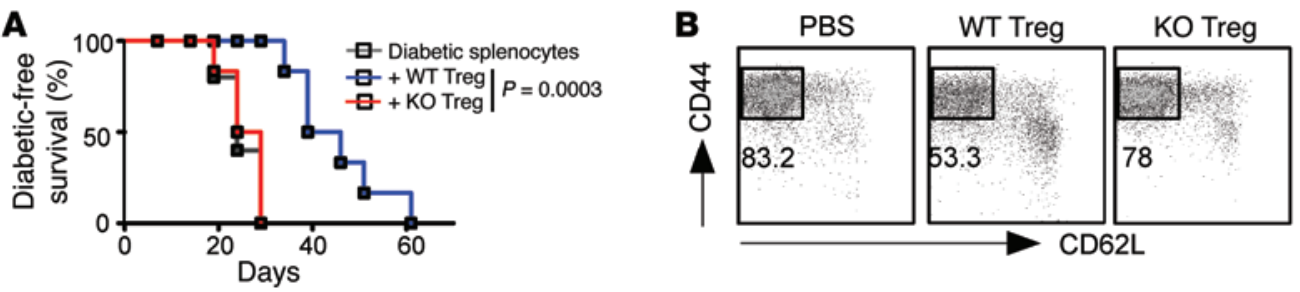

C

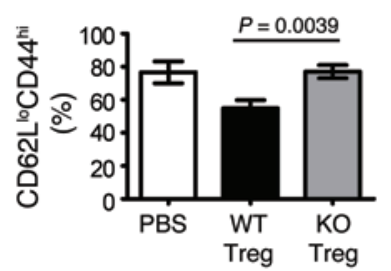

D
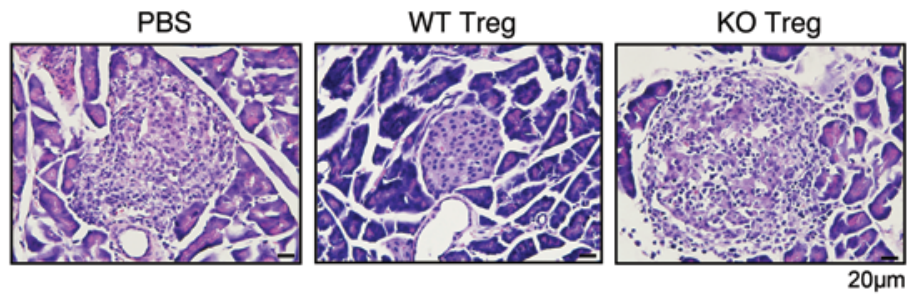

\section{E}

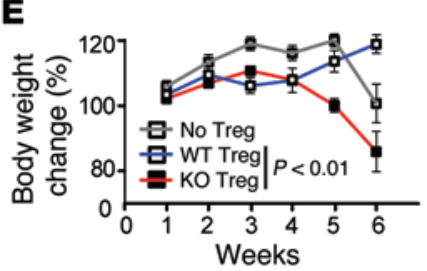

$\mathbf{F}$
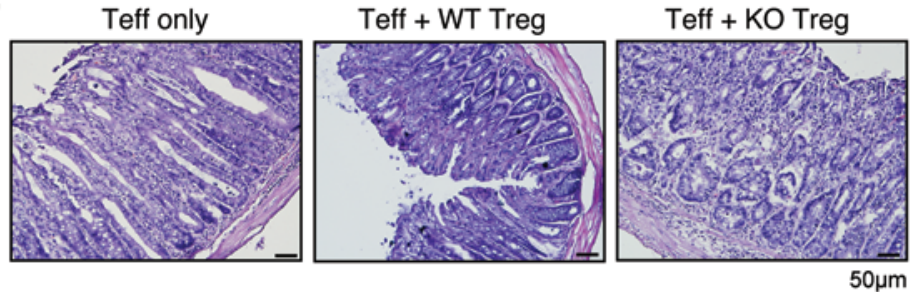

H
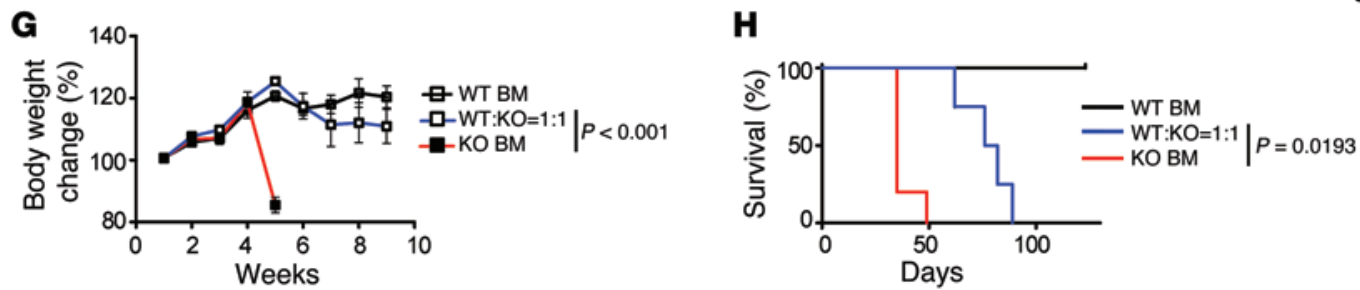

Figure 5. Failure of GP96 KO Tregs to suppress T cell-mediated autoimmune diseases. (A) $6 \times 10^{6} \mathrm{CD} 25^{+} \mathrm{T}$ cell-depleted splenocytes from diabetogenic NOD mice were adoptively transferred into NOD Rag-1- mice, along with purified WT or KO Tregs. After transfer, blood glucose was monitored kinetically. (B and C) Analysis of CD4+CD44 ${ }^{\text {hi }} \mathrm{CD} 62 \mathrm{~L}^{10}$ cells in the pancreatic draining LNs of the recipient mice. Two-tailed Student's $t$ test was used for statistic analysis. One of the 3 representative experiments is shown. (D) H\&E staining of pancreatic sections from the recipient mice 2 weeks after the adoptive transfer. (E-H) Suppression of colitis. (E) CD4+CD25-CD45Rb hi T cells isolated from pooled spleen and LNs of NOD mice were transferred i.v. into NOD Rag ${ }^{-1-}$ mice along with either WT or KO Tregs. After transfer, the body weight of the recipient mice was examined weekly. Data represent 2 independent experiments. (F) H\&E staining of colon section from the mice 6 weeks after T cell transfer. (G and $\mathbf{H}$ ) Rescue of autoimmune colitis by WT BM cells. BM cells from WT or KO mice or mixture of the $2(\mathrm{WT} / \mathrm{KO}=1: 1)$ were transfused into lethally irradiated recipients (NOD Rag ${ }^{-/-}$mice) followed by weekly examination. (C) Body weight. (H) Survival. Data represent results from 3 independent experiments. In experiments depicted in E-H, 2-way ANOVA was used for determining statistical significance on the body weight change; a log-rank (Mantel-Cox) test was used for statistical analysis of mouse survival.

\section{Discussion}

Protein chaperones, known traditionally as hsps, constitute the protein-folding machinery in the cell that plays critical roles in many aspects of cellular function $(48,49)$. Unfolded protein precursors were once thought to harbor common structural patterns for recognition by hsp, which then carries out the redundant polypeptide-folding reaction to facilitate protein maturation. However, emerging genetic and biochemical studies have demonstrated that there exists exquisite substrate specificity for the action of chaperones. For example, the cytosolic HSP9O is preferentially involved in folding proteins implicated in cellular fate/ organization, cellular transport, metabolism, and transcription, which cannot be compensated by other hsps (50,51). Moreover, through its ability to buffer mutations, HSP9O appears to be an important capacitor for morphogenic evolution and oncogenesis $(52,53)$. Understanding the substrate specificity of hsps thus becomes an important task for uncovering the underlying biolo- gy of chaperones in order to target them for therapeutic purposes of human diseases.

Our study focuses on the roles of GP96, the ER paralog of the cytosolic HSP90, in immune tolerance. We demonstrate that Treg-intrinsic GP96 plays a vital role in maintaining peripheral tolerance. Without it, Tregs appear to develop normally, but their suppressive function is severely compromised. Since GP96 is a protein chaperone, our mechanistic focus naturally was to determine whether the defect of GP96 clienteles could be responsible for the observed phenotype. A large number of GP96 clients are type I transmembrane proteins with leucine-rich repeats such as TLRs $(18,19,45,54,55)$ and the GP-IX molecule (20). In addition, GP96 is also an obligate chaperone for multiple integrins (22). TLRs can modulate responding cells to Treg-mediated suppression (56), but they are not required for steady-state immune tolerance (57), as demonstrated by lack of autoinflammatory disease in Myd88 and Trif double-KO mice, which have abolished all 

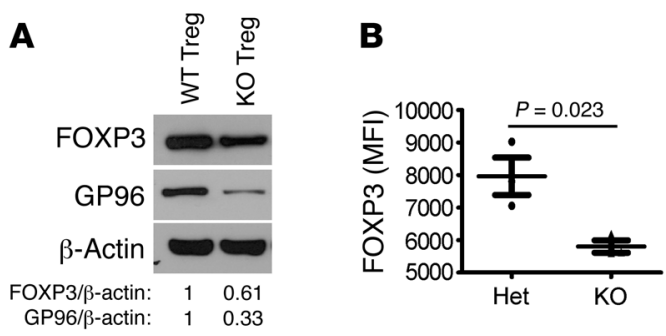

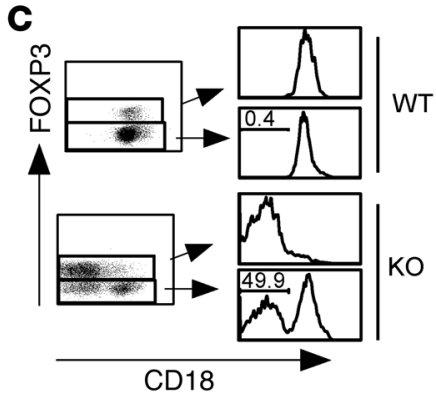

$\mathbf{F}$

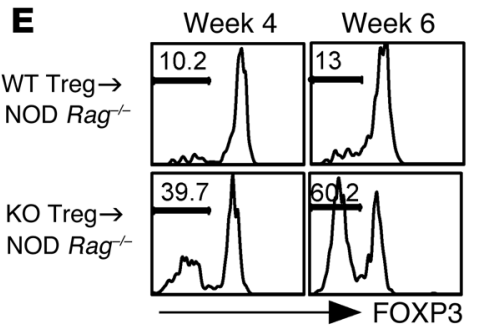

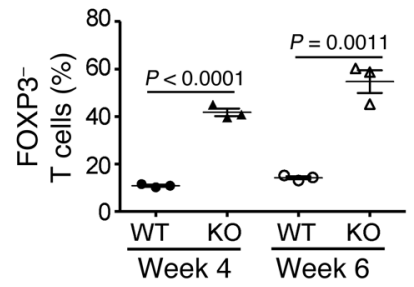

G

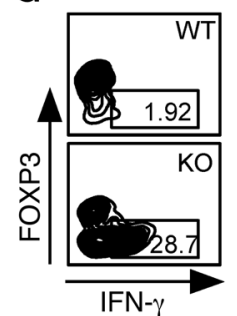

D

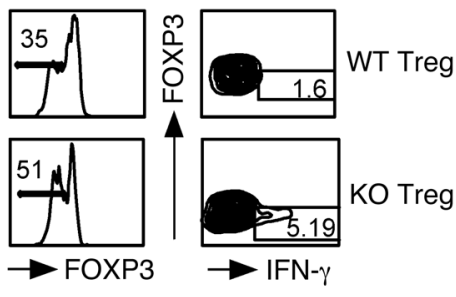

H

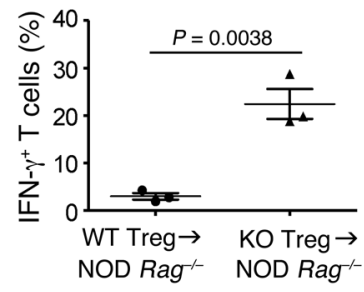

Figure 6. GP96-null Tregs lose FOXP3 expression and convert to IFN- $\gamma$-producing ex-FOXP3 T cells. (A) FOXP3 and GP96 expression in Tregs from WT and $\mathrm{KO}$ mice was determined by Western blot. Data represent 2 independent experiments. (B) Mean fluorescence intensity (MFI) of FOXP3 stain of Tregs from Het and KO mice. Data are represented as mean \pm SEM. (C) Surface expression of $\beta_{2}$ integrin (CD18) on Tregs and Teff cells from WT and KO mice was determined by flow cytometry. Numbers represent percentages of CD18- cells in the gated populations. (D) CD4+CD25+ Tregs from WT and KO mice were stimulated with plate-bound antibodies against CD3 and CD28 plus IL-12 for 3 days, followed by IC staining for FOXP3 and IFN- $\gamma$. Numbers indicate percentages of indicated cells in the entire population. Two independent experiments were performed with similar findings. (E and F) FACS-sorted CD4 ${ }^{+}$FOXP3GFP ${ }^{+}$ Tregs $\left(2 \times 10^{5}\right)$ from 3-week-old WT or KO mice were transferred to NOD Rag ${ }^{-1-}$ mice. IC FOXP3 levels in CD4 T cells from the peripheral blood were then analyzed 4 and 6 weeks after the adoptive transfer. The percentage of FOXP3- cells within CD4+ cells (mean \pm SEM) was plotted in F. (G and $\mathbf{H})$ IFN- $\gamma$ levels (percentages) in CD4 T cells from splenocytes of the mice in $\mathbf{E}$ and $\mathbf{F}$ above were analyzed. Data in $\mathbf{C}-\mathbf{F}$ represent 4 independent experiments. Two-tailed Student's $t$ test was used for statistical analysis between groups.

TLR signaling (58). $\alpha_{\mathrm{v}}$ integrin is a client of GP96, but pan-deletion of integrins in the hematopoietic system in mice does not induce fatal immunopathology (59). In addition, we also found GP96 KO $\mathrm{T}$ cells had no perturbation of mTORC1 signaling (Supplemental Figure 6), arguing against a defect in the basic cell metabolism as being responsible for the functional loss of Tregs.

Importantly, we found that GP96 is an obligate molecular chaperone for GARP - a cell-surface-docking receptor for mLTGF- $\beta$ (41, 42). The expression of mLTGF- $\beta$ is the function of 2 major cell types in the hematopoietic system, platelets and FOXP3 $^{+}$Tregs, due to the restricted expression pattern of GARP. However, the functional significance of surface TGF- $\beta$ in Tregs in vivo remains unclear. The question cannot be addressed by genetic deletion of TGF- $\beta$ from Tregs, since this strategy would abolish the function of all 3 forms of TGF- $\beta$. Given the fact that $\alpha_{\mathrm{v}}$ integrin has been implicated in TGF- $\beta$ activation, we hypothesized that GP96-null Tregs had significant reduction of the production of active TGF- $\beta$ due to the abrogation of both GARP and $\alpha_{\mathrm{v}}$ integrin. Three pieces of evidence support this hypothesis, including the following: (a) active TGF- $\beta$ was significantly reduced from KO GP96-null Tregs (Figure 8, A and B); (b) unlike WT Tregs, KO Tregs failed to induce Th17 cell differentiation in a coculture experiment that depended on TGF- $\beta$ (Figure 8C); and (c) GP96 KO naive T cells failed to convert to Tregs in vivo (Figure 8, D and E). We thus propose that GP96 play essential roles in maintaining TGF- $\beta$ bioavailability and Treg function by chaperoning both GARP and integrin.
Our study strongly suggests that the fundamental role of mLTGF- $\beta$ in Tregs is to confer immune tolerance in vivo. Several questions remain unanswered. First, it is unclear why TGF- $\beta$ on the surface of Tregs is so important in the biology of this cell type. Although speculative, this question may have to do with the high local concentration of TGF- $\beta$ required for Treg function in vivo. The Treg-specific GARP may serve as a "sponge" not only to concentrate autocrine TGF- $\beta$, but also to absorb soluble LTGF- $\beta$ from the local milieu to execute the immunosuppressive function. This argument is consistent with the fact that there is no apparent pathology associated with TGF- $\beta$ deletion from Tregs (40). It can be argued that GARP on the surface of TGF- $\beta$ KO Tregs remains capable of acquiring TGF- $\beta$ from other non-Tregs. It is also interesting to note that such a mechanism may not be restricted to Tregs (42). Second, defect in mLTGF- $\beta$ generation is most likely not the only underlying mechanism for the functional defect of GP96 KO Tregs. For example, we did observe a reduction of both FOXP3 and CD25 from KO Tregs, which may indicate that KO Tregs are not as competitively fit as WT Tregs (14), thus contributing to the decreased suppressive function. More importantly, GARP-associated mLTGF- $\beta$ still requires activation to be biologically active. mLTGF- $\beta$ can be activated by $\alpha_{v} \beta_{6}$ and $\alpha_{v} \beta_{8}$ integrins either in trans or cis (25), suggesting that Treg-derived $\alpha_{\mathrm{v}}$ integrins also participate in controlling TGF- $\beta$ bioavailability. In addition, $\beta_{2}$ integrin, another client of GP96, has been shown to augment Treg function via TGF- $\beta$ (60). Since GP96 controls the expression of GARP as well as $\alpha_{\mathrm{v}}$ and $\beta_{2}$ integrins, this explains why its absence from Tregs results 
A
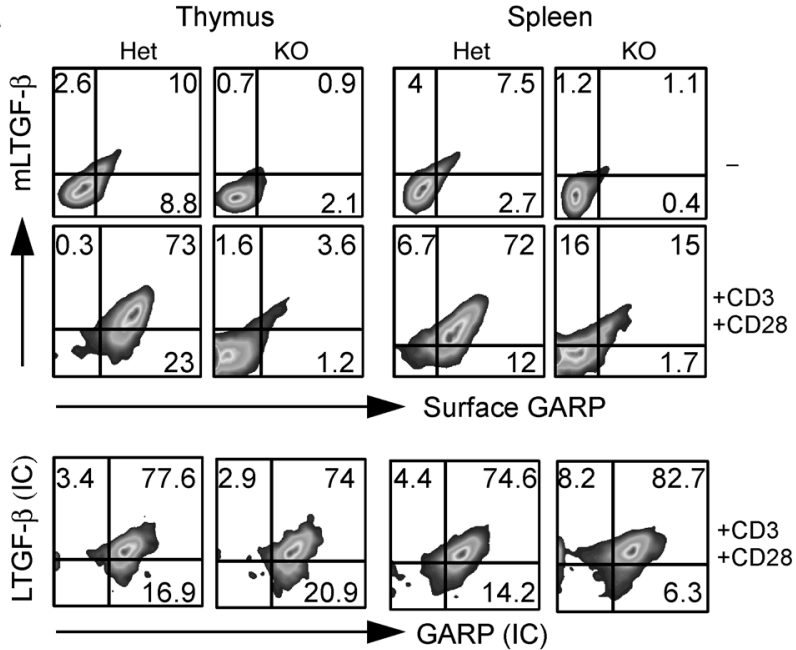
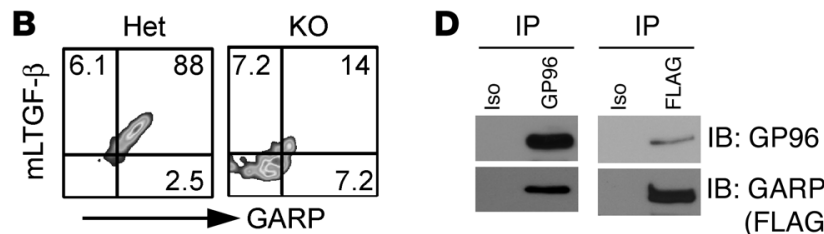

(FLAG)

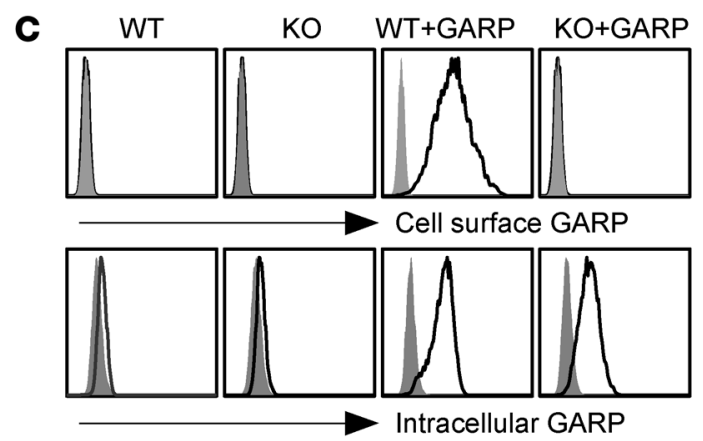

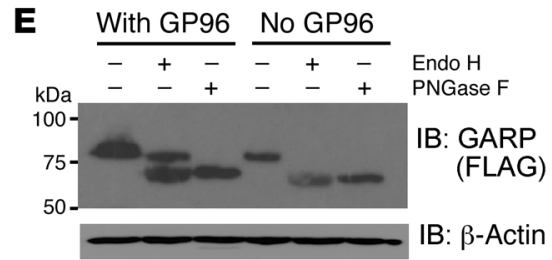

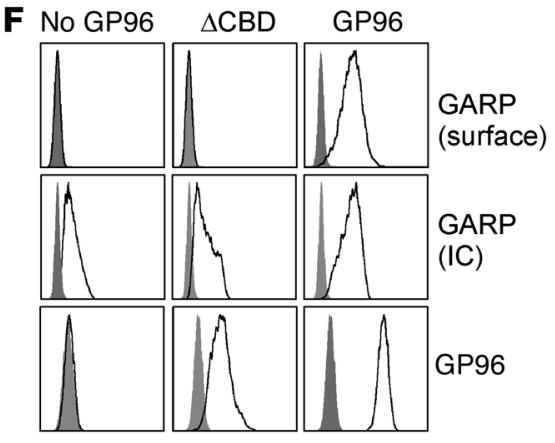

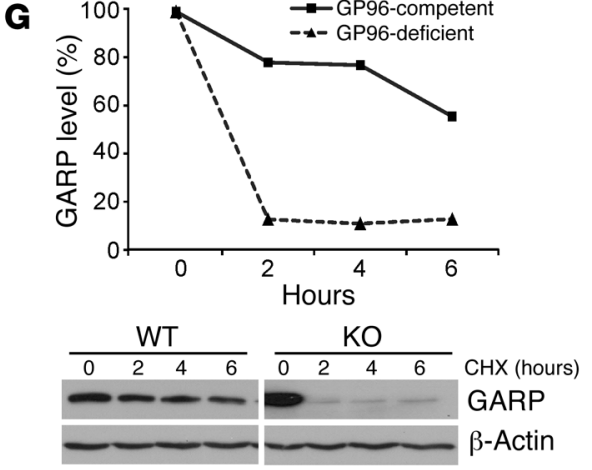

Figure 7. GP96 is a critical chaperone for cell-surface expression of GARP and mLTGF- $\beta$. (A) Flow cytometry analysis of GARP and mLTCF- $\beta$ expression on $\mathrm{CD}^{+}{ }^{+} \mathrm{FXXP3}^{+}$Tregs from the thymus and spleen either immediately after isolation or after anti-CD3 and anti-CD28 antibody treatment for 24 hours. (B) Flow cytometry analysis of GARP and mLTCF- $\beta$ expression on CD41+ platelets. Two experiments were performed with similar findings. (C) Surface expression of GARP or IC GARP (solid line, open histogram) was analyzed in WT and GP96-deficient cells transduced with GARP-FLAC. Gray histograms represent isotype controls. Data from $\mathbf{A}$ and $\mathbf{C}$ represent 4 independent experiments. (D) Immunoblot of GP96 and GARP-FLAG following immunoprecipitation with GP96 antibody (left) or FLAG antibody (right) from GARP-FLAG-overexpressed cell lysates. Data represent 4 independent experiments. (E) The sensitivity of GARP to $\mathrm{N}$-glycase Endo $\mathrm{H}$ and PNGase $\mathrm{F}$ in WT and GP96 mutant cells. Data are representative of 2 independent experiments. (F) GP96 mutant cells were transduced with full-length GP96 or CBD-deleted GP96 ( $\triangle \mathrm{CBD}$ ), followed by examination of cell-surface and IC GARP. Data represent 3 independent experiments. (G) Half-life analysis of GARP-FLAG by immunoblot in WT and GP96-deficient cells following cycloheximide (CHX) treatment. Graph represents densitometric value of the full-length GARP, with time 0 set at 100\%. Data represent 2 independent experiments.

in reduced bioavailability of TGF- $\beta$ and the ensuing fatal immunopathology. Our study can also explain why deletion of GARP alone from $\mathrm{T}$ cells is not expected to have an apparent pathological consequence (61). In that scenario, some level of surface LTGF- $\beta$ still exists due to its possible association with LTBP, integrins, and other extracellular matrix proteins, allowing integrin-dependent TGF- $\beta$ activation to continue. The dual roles of GP96 in controlling both surface availability of LTGF- $\beta$ and its activation may have important therapeutic implications against a variety of diseases whose underlying pathogenesis is TGF- $\beta$ dysregulation (62).

Finally, the significance of our finding that GP96 controls expression of surface TGF- $\beta$ via folding GARP likely goes beyond immune tolerance. For example, the surface expression of TGF- $\beta$ in cancer has long been recognized $(63,64)$, but its biological significance is elusive. GP96 overexpression has already been reported to confer poor prognosis for a variety of cancer types $(65$,
66). Future studies into the functional link between GP96 upregulation and TGF- $\beta$ signaling may prove fruitful in uncovering new mechanisms of immune tolerance as well as cancer biology.

\section{Methods}

Mice. Hsp $90 \mathrm{Ob}^{1 / / \mathrm{f}}$ mice were backcrossed to the NOD background for 7-10 generations and were further crossed with NOD/ShiLt-Tg(Foxp3EGFPCre) $1 \mathrm{cJbs} / J$ mice (The Jackson Laboratory) to generate either

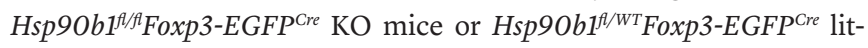
termates (designated as Het). Platelet-specific Hsp90b1 KO (GP96 KO) mice were generated by crossing with C57BL/6-Tg(Pf4-Cre) Q3Rsko/J mice (The Jackson Laboratory). $\mathrm{T}$ cell-specific deletion of GP96 on a C57BL/6 and NOD background was accomplished by crossing $\mathrm{Hsp} 90 \mathrm{Ob} 1^{\mathrm{Al} / \mathrm{l}}$ mice with $\mathrm{Cd} 4$-Cre transgenic mice (The Jackson Laboratory). All mice were maintained by the Division of Laboratory Animal Resources of the Medical University of South Carolina. 
A

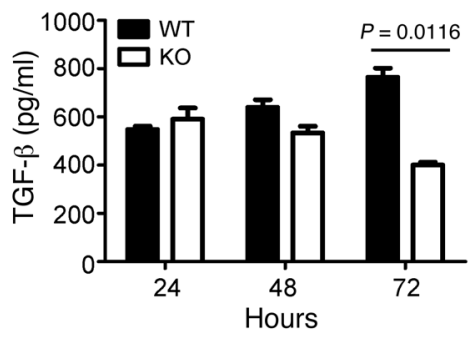

D WT naive T cell $\mathrm{KO}$ naive T cell

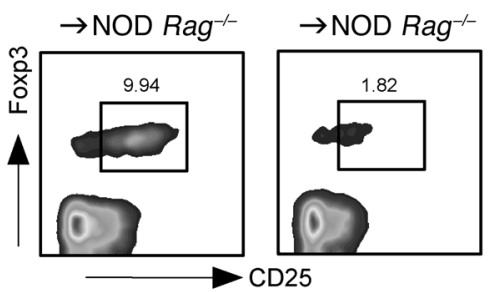

B

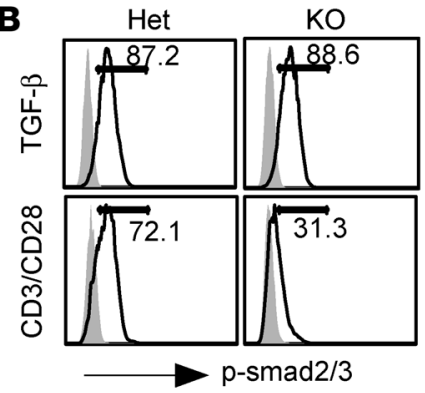

E

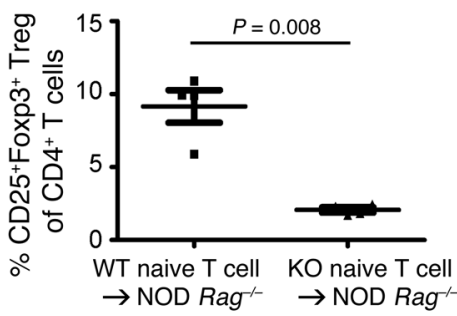

C

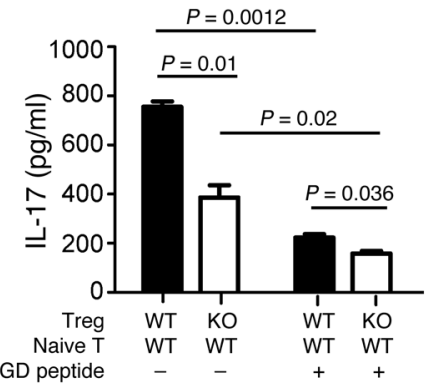

$\mathbf{F}$

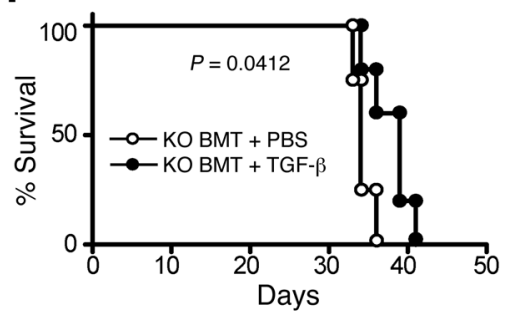

Figure 8. GP96 controls mTGF- $\beta$ bioactivity. (A) MACS-purified CD4+CD25+ Tregs were stimulated with plate-bound antibody against CD3 (1 $\mu \mathrm{g} / \mathrm{ml})$ and CD28 $(0.5 \mu \mathrm{g} / \mathrm{ml})$ for indicated times. TGF- $\beta$ levels in the culture supernatant were quantitated by ELISA. Data represent 3 independent experiments. (B) CD4 ${ }^{+}$CD25 $5^{+}$Tregs were stimulated with TCF- $\beta 1(1 \mathrm{ng} / \mathrm{ml})$ for 45 minutes or antibodies against CD 3 and CD28 for 24 hours. Cells were then fixed and stained intracellularly for $\mathrm{p}-\mathrm{Smad2} / 3$. Numbers indicate percentages of indicated cells in the entire population. Data represent 3 independent experiments. (C) CD4 ${ }^{+}$CD25+ Tregs were activated with plate-bound anti-CD3 antibody $(2 \mu \mathrm{g} / \mathrm{ml})$ for 2 to 3 days, followed by irradiation (2000 cGy) and coculturing with CD4+CD25- naive T cells for 3 days, with or without RGD peptide. The level of IL-17A in the culture supernatant was determined by ELISA. Data represent

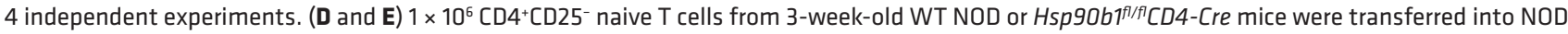
$\mathrm{Rag}^{-1-}$ mice. Four weeks later, induced Tregs $\left(\mathrm{CD}^{+}{ }^{+} \mathrm{CD} 25^{+} \mathrm{FOXP3}^{+}\right)$were examined by flow cytometry (D) and quantified (E) (each dot represents 1 individual mouse). Data represent 3 independent experiments. (F) Irradiated NOD Rag ${ }^{-/-}$recipient mice were transplanted with KO BM. Seven days later, mice were injected i.p. with recombinant TGF- $\beta 2(0.2 \mu \mathrm{g} / 100 \mu \mathrm{l})$ daily for 5 days, followed by once every 3 days. Survival of the mice was monitored. Data represent 2 independent experiments. Statistical analyses were performed with 2-tailed Student's $t$ test for $(\mathbf{A}, \mathbf{C}$, and $\mathbf{E})$ and log-rank test (F).

Antibody, BrdU, and flow cytometry. Spleen, LN, and thymus were minced, and a single-cell suspension was made. After Fc-receptor blocking, cells were stained for surface markers and IC molecules. Antibodies against CD4 (RM4-5), FOXP3 (FJK-16), CD69d (R1-2), CD134 (OX-86), CTLA-4 (UC10-4B9), IL-4 (11B11), IL-2 (JES6-5H4), IFN- $\gamma$ (XMG1.2), IL-6 (MP5-20F3), IL-10 (JES5-16E3), and TNF- $\alpha$ (Mp6-XT22) were purchased from eBioscience; antibodies against CD25 (PC61), CD62L (ME-14), CD44 (1M7), and IL-17A(TC11-18H10) as well as the Caspase-3, Active Form, Apoptosis Kit (cat. no. 550914) were obtained from BD Biosciences - Pharmingen; anti-LAP-TGF- $\beta$ (Tw7-16B4) and anti-CD103 (2E7) antibodies were ordered from BioLegend. Smad2 (pS465/pS467)/Smad3 (pS423/pS425) (O72-670) antibodies were obtained from BD Biosciences.

BrdU was administered to mice in $150 \mu \mathrm{l}$ PBS $(10 \mathrm{mg} / \mathrm{ml})$ by intraperitoneal injection. Two days later, lymphocytes from various organs were prepared and surface stained with indicated markers on ice for 30 minutes. BrdU incorporation was then assessed per the manufacturer's protocol (BrdU flow kit, BD Biosciences - Pharmingen). After staining, cells were washed with BD Perm/Wash Buffer and run on FACSverse within 12 hours.

To stain cytokines intracellularly, cells were fixed with 4\% PFA and permeabilized with $0.25 \%$ saponin before incubation with appropriate antibodies. FOXP3 IC staining was done using a commercial FOXP3/Transcription Factor Staining Buffer Set (eBioscience). For IC detection of GP96, cells were stained first for surface markers, then fixed in $4 \%$ formalin/PBS, followed by permeabilization using ice-cold
$\mathrm{MeOH}$. Nonspecific binding was blocked with $10 \%$ goat serum, and IC GP96 was stained with a rat monoclonal antibody (9G10, Stressgen), followed by fluorochrome-labeled anti-rat secondary antibody.

For detection of phosphorylated signaling molecules, lymphocytes were rested in complete medium for 1 hour. They were either stimulated with plate-bound anti-CD3 antibody $(5 \mu \mathrm{g} / \mathrm{ml})$ plus antiCD28 antibody $(5 \mathrm{~g} / \mathrm{ml})$ for 24 hours or directly fixed without stimulation. The fixation was done with Phosflow Lyse/Fix buffer, followed by permeabilization with Phosflow Perm Buffer III (BD Biosciences) and staining with antibodies against p-Smad2/3, phosphorylated S6 at Ser235 and Ser236 (D57.2.2E; Cell Signaling Technology), or phosphorylated 4E-BP1 at Thr37 and Thr46 (236B4; Cell Signaling Technology). Cells were acquired using BD FACSVerse (BD), and results were analyzed with FlowJo software (Tree Star).

Histology and multiplex cytokine assay. Organs from $\mathrm{KO}$ and Het mice were fixed with $3.7 \%$ formalin. After dehydration with $30 \%$ sucrose, tissues were then embedded in OCT, sectioned, and processed for H\&E staining according to standard protocols. Mouse serum was collected by tail-vein bleeding and frozen at $-80^{\circ} \mathrm{C}$ before experimentation. Serum levels of TNF- $\alpha$, IL-6, IFN- $\gamma$, IL-4, IL-17, IL-2, IL-10, and IL-13 were determined using the Multiplexing LASER Bead Assay (Eve Technologies). Serum levels of TGF- $\beta$ were measured with the mouse TGF- $\beta 1$ Quantikine ELISA Kit (R\&D Systems).

In vitro suppression assay. A total of $5 \times 10^{4} \mathrm{CFSE}-\mathrm{V} 450-$ labeled naive $\mathrm{T}\left(\mathrm{CD} 4^{+} \mathrm{CD} 25^{-}\right)$cells were stimulated with $2 \mu \mathrm{g} / \mathrm{ml}$ anti-CD3$\varepsilon$ antibody in the presence of $5 \times 10^{4}$ irradiated NOD $\mathrm{Rag}^{-/-}$spleno- 
cytes. Tregs from WT and Hsp90b1 $1^{f / A}$-Foxp3-EGFP ${ }^{C r e} \mathrm{KO}$ mice were isolated with MACS Treg isolation kit and added to the culture to achieve Treg/Teff cell ratios of 1:1 to 1:8. Teff cells only, without Tregs, were used as a positive control for $\mathrm{T}$ cell proliferation. Three days after stimulation, CFSE dilutions of $\mathrm{T}$ cells were analyzed and quantified by flow cytometry.

Diabetes model. Splenocytes from NOD mice were incubated with anti-CD25 MACS beads and depleted of CD25+ cells with the MACS LD column. $6 \times 10^{6} \mathrm{CD} 25^{-} \mathrm{T}$ cells per mouse were adoptively transferred, with or without $2 \times 10^{5} \mathrm{CD} 4^{+} \mathrm{CD} 25^{+}$Tregs (WT or GP96 KO), i.v. into NOD $\mathrm{Rag}^{-/-}$mice. Blood glucose concentrations were then monitored kinetically. A glucose value of $200 \mathrm{mg} / \mathrm{dl}$ or more was defined as diabetic. Autoimmune destructions of pancreatic islet cells were verified by histology.

$T$ cell transfer model of colitis. A total of $5 \times 10^{5} \mathrm{CD} 4{ }^{+} \mathrm{CD} 25$ $\mathrm{CD} 45 \mathrm{Rb}^{\text {hi }}$ Teff cells per mouse, with or without $2 \times 10^{5} \mathrm{CD} 4^{+} \mathrm{CD} 25^{+}$ Tregs, were i.v. transferred into NOD $\mathrm{Rag}^{-/}$mice. Following the transfer, the body weight of mice was measured weekly. At the conclusion of the experiments, mice were sacrificed and organs including colons were examined histologically for evidence of colitis.

In vivo Treg stability assay. Pooled splenocytes from WT or KO mice were stained with CD4, followed by 2 rounds of sorting of $\mathrm{CD}^{+}{ }^{+} \mathrm{FOXP} 3 \mathrm{EGFP} \mathrm{PI}^{+}$Tregs, with MoFlo Astrios (Beckman Coulter). A level of $99 \%$ purity of Tregs was achieved. A total of $2 \times 10^{5}$ viable Tregs were then adoptively transferred via i.v. route to NOD $\mathrm{Rag}^{-1}$ mice. Tregs in the recipient mice were kinetically analyzed by flow cytometry based on Foxp3-EGFP intensity or IC staining of FOXP3.

Treg and Th17 cell conversion assay. This was performed based on the published protocol (61) without substantial modifications. In brief, to determine the level of active TGF- $\beta$ production by Tregs, WT or GP96 KO CD4 ${ }^{+} \mathrm{CD} 25^{+}$Tregs were activated with plate-bound anti-CD3 antibody $(2 \mu \mathrm{g} / \mathrm{ml})$ for 2 to 3 days, followed by irradiation $(2,000 \mathrm{cGy})$ and coculturing with WT CD $4^{+} \mathrm{CD} 25^{-}$naive T cells at a 1:1 ratio for 3 days. To induce Tregs, the cultures were supplemented with recombinant human $\mathrm{IL}-2(100 \mathrm{U} / \mathrm{ml})$ and soluble anti-CD3 antibody $(1 \mu \mathrm{g} / \mathrm{ml})$. For Th17 cell induction, the cells were stimulated additionally with IL-6 (10 ng/ml). The level of IL-17A in the culture supernatant was determined by ELISA.

Generation of BM chimeras. BM from WT or KO mice was harvested, followed by red blood cell lysis and T cell depletion with CD90.2
MACS beads. T cell-depleted BM cells were then infused into 600 cGy-irradiated NOD $\mathrm{Rag}^{-/-}$recipient mice by tail-vein injection.

TSDR methylation assay. A quantitative real-time PCR method was used to analyze the methylation status of the key CpG dinucleotide in the TSDR of the FOXP3 gene promoter, where demethylation has been shown to correlate with stable Tregs. $\mathrm{CD} 4{ }^{+} \mathrm{CD} 25^{+}$Tregs and $\mathrm{CD} 4{ }^{+} \mathrm{CD} 25^{-}$naive $\mathrm{T}$ cells were MACS purified and treated with bisulfite using the EZ DNA Methylation-Direct Kit (Zymo Research) according to the manufacturer's protocol. Purified bisulfite-treated DNA was used in a quantitative PCR reaction. Primers and probes were synthesized by Integrated DNA Technologies, which revealed the following sequences: forward primer, 5'-GGTTTATATTTGGGTTTTGTTGTTATAATTT-3'; reverse primer, 5'-ССССТTСТСТTССТССТТАТTACC-3'; methylated (CG) probe, 5'-TGACGTTATGGCGGTCG-3'; and unmethylated (TG) probe, 5'-ATTGATGTTATGGTGGTTGGA-3'.

Statistics. Statistical analysis was done using Prism software (GraphPad Software). Two-tailed Student's $t$ test was performed for comparisons of experimental groups, whereas 2-way ANOVA was applied for determining statistical significance across multiple points, such as in a time-course study. A log-rank (Mantel-Cox) test was used to compare survival between different groups of mice. A $P$ value of less than 0.05 was considered statistically significant.

Study approval. Animal studies were approved by the Institutional Animal Care and Use Committee of the Medical University of South Carolina per established guidelines.

\section{Acknowledgments}

We thank Philip Howe for helpful input and the members of our laboratories and the Cancer Immunology Program at the Hollings Cancer Center for stimulating discussion during the course of the study. The work was supported by NIH grants AIO77283 and AI070604 (to Z. Li) and by the Flow Cytometry and Cell Sorting Shared Resource, Hollings Cancer Center, Medical University of South Carolina (P30 CA138313). Z. Li is the Abney Chair Remembering Sally Abney Rose in Stem Cell Biology and Therapy and is supported by the SmartState Endowed Chair Program of South Carolina, USA.

Address correspondence to: Zihai Li, Medical University of South Carolina, 86 Jonathan Lucas Street, Charleston, South Carolina 29425, USA. Phone: 843.792.1034; E-mail: zihai@musc.edu.
1. Sakaguchi S. Regulatory T cells: history and perspective. Methods Mol Biol. 2011;707:3-17.

2. Brunkow ME, et al. Disruption of a new forkhead/winged-helix protein, scurfin, results in the fatal lymphoproliferative disorder of the scurfy mouse. Nat Genet. 2001;27(1):68-73.

3. Fontenot JD, Rasmussen JP, Williams LM, Dooley JL, Farr AG, Rudensky AY. Regulatory T cell lineage specification by the forkhead transcription factor foxp3. Immunity. 2005;22(3):329-341.

4. Fontenot JD, Gavin MA, Rudensky AY. Foxp3 programs the development and function of $\mathrm{CD} 4{ }^{+} \mathrm{CD} 25^{+}$regulatory T cells. Nat Immunol. 2003;4(4):330-336.

5 . Lahl K, et al. Selective depletion of Foxp $3^{+}$regulatory $\mathrm{T}$ cells induces a scurfy-like disease. JExp Med. 2007;204(1):57-63.

6. Kim JM, Rasmussen JP, Rudensky AY. Regula- tory $\mathrm{T}$ cells prevent catastrophic autoimmunity throughout the lifespan of mice. Nat Immunol. 2007;8(2):191-197.

7. Bennett CL, et al. The immune dysregulation, polyendocrinopathy, enteropathy, X-linked syndrome (IPEX) is caused by mutations of FOXP3. Nat Genet. 2001;27(1):20-21.

8. Chatila TA, et al. JM2, encoding a fork headrelated protein, is mutated in X-linked autoimmunity-allergic disregulation syndrome. J Clin Invest. 2000;106(12):R75-R81.

9. Wildin RS, et al. X-linked neonatal diabetes mellitus, enteropathy and endocrinopathy syndrome is the human equivalent of mouse scurfy. Nat Genet. 2001;27(1):18-20.

10. Sakaguchi S. Naturally arising $\mathrm{CD} 4^{+}$regulatory $\mathrm{T}$ cells for immunologic self-tolerance and negative control of immune responses. Annu Rev Immunol.
2004;22:531-562.

11. Sakaguchi S, Yamaguchi T, Nomura T, Ono M. Regulatory T cells and immune tolerance. Cell. 2008;133(5):775-787.

12. Wan YY, Flavell RA. Regulatory T-cell functions are subverted and converted owing to attenuated Foxp3 expression. Nature. 2007;445(7129):766-770.

13. Williams LM, Rudensky AY. Maintenance of the Foxp3-dependent developmental program in mature regulatory $\mathrm{T}$ cells requires continued expression of Foxp3. Nat Immunol. 2007;8(3):277-284.

14. Fontenot JD, Rasmussen JP, Gavin MA, Rudensky AY. A function for interleukin 2 in Foxp3expressing regulatory T cells. Nat Immunol. 2005;6(11):1142-1151.

15. Hori S, Nomura T, Sakaguchi S. Control of regula- 
tory T cell development by the transcription factor Foxp3. Science. 2003;299(5609):1057-1061.

16. Hori S. Lineage stability and phenotypic plasticity of Foxp3(+) regulatory T cells. Immunol Rev. 2014;259(1):159-172.

17. Yang Y, Li Z. Roles of heat shock protein gp96 in the ER quality control: redundant or unique function? Mol Cells. 2005;20(2):173-182.

18. Yang $\mathrm{Y}$, et al. Heat shock protein gp96 is a master chaperone for toll-like receptors and is important in the innate function of macrophages. Immunity. 2007;26(2):215-226.

19. Liu B, et al. Folding of Toll-like receptors by the HSP90 paralogue gp96 requires a substratespecific cochaperone. Nat Commun. 2010;1:79.

20. Staron M, et al. Heat shock protein gp 96 chaperones platelet glycoprotein Ib-IX-V complex and protects mice from Bernard-Soulier syndrome-like platelet disorder. Blood. 2011;117(26):7136-7144.

21. Liu B, et al. Essential roles of grp94 in gut homeostasis via chaperoning canonical Wnt pathway. Proc Natl Acad Sci U S A. 2013;110(17):6877-6882.

22. Staron M, et al. gp96, an endoplasmic reticulum master chaperone for integrins and Toll-like receptors, selectively regulates early $\mathrm{T}$ and $\mathrm{B}$ lymphopoiesis. Blood. 2010;115(12):2380-2390.

23. Tran DQ, Andersson J, Wang R, Ramsey H, Unutmaz D, Shevach EM. GARP (GARP) is essential for the surface expression of latent TGF-beta on platelets and activated FOXP3 ${ }^{+}$ regulatory T cells. Proc Natl Acad Sci U S A. 2009;106(32):13445-13450.

24. Stockis J, Colau D, Coulie PG, Lucas S. Membrane protein GARP is a receptor for latent TGF- $\beta$ on the surface of activated human Treg. Eur J Immunol. 2009;39(12):3315-3322.

25. Wang R, Zhu J, Dong X, Shi M, Lu C, Springer TA. GARP regulates the bioavailability and activation of TGFß. Mol Biol Cell. 2012;23(6):1129-1139.

26. Zhou $\mathrm{X}$, et al. Selective miRNA disruption in $\mathrm{T}$ reg cells leads to uncontrolled autoimmunity. JExp Med. 2008;205(9):1983-1991.

27. Li MO, Sanjabi S, Flavell RA. Transforming growth factor-beta controls development, homeostasis, and tolerance of $T$ cells by regulatory $\mathrm{T}$ cell-dependent and -independent mechanisms. Immunity. 2006;25(3):455-471.

28. Takimoto T, et al. Smad 2 and Smad3 are redundantly essential for the TGF- $\beta$-mediated regulation of regulatory $\mathrm{T}$ plasticity and $\mathrm{Th} 1$ development. J Immunol. 2010;185(2):842-855.

29. Shull MM, et al. Targeted disruption of the mouse transforming growth factor- $\beta 1$ gene results in multifocal inflammatory disease. Nature. 1992;359(6397):693-699.

30. Gorelik L, Flavell RA. Abrogation of TGFbeta signaling in $\mathrm{T}$ cells leads to spontaneous $\mathrm{T}$ cell differentiation and autoimmune disease. Immunity. 2000;12(2):171-181.

31. Liu B, Li Z. Endoplasmic reticulum HSP9Ob1 (gp96, grp94) optimizes B-cell function via chaperoning integrin and TLR but not immunoglobulin. Blood. 2008;112(4):1223-1230.

32. Chaudhry A, et al. Interleukin-10 signaling in regulatory $\mathrm{T}$ cells is required for suppression of
Th17 cell-mediated inflammation. Immunity. 2011;34(4):566-578.

33. Floess $\mathrm{S}$, et al. Epigenetic control of the foxp3 locus in regulatory T cells. PLoS Biol. 2007;5(2):e38.

34. Miyao T, et al. Plasticity of Foxp3(+) T cells reflects promiscuous Foxp3 expression in conventional $\mathrm{T}$ cells but not reprogramming of regulatory T cells. Immunity. 2012;36(2):262-275.

35. Yadav M, et al. Neuropilin-1 distinguishes natural and inducible regulatory $\mathrm{T}$ cells among regulatory T cell subsets in vivo. JExp Med. 2012;209(10):1713-1722.

36. Liu Y, Zhang P, Li J, Kulkarni AB, Perruche S, Chen $W$. A critical function for TGF- $\beta$ signaling in the development of natural $\mathrm{CD} 4^{+} \mathrm{CD} 25^{+} \mathrm{Foxp}^{+}$regulatory T cells. Nat Immunol. 2008;9(6):632-640.

37. Marie JC, Letterio JJ, Gavin M, Rudensky AY. TGF- $\beta 1$ maintains suppressor function and Foxp3 expression in $\mathrm{CD} 4{ }^{+} \mathrm{CD} 25^{+}$regulatory $\mathrm{T}$ cells. JExp Med. 2005;201(7):1061-1067.

38. Li MO, Wan YY, Flavell RA. T cell-produced transforming growth factor-beta1 controls $\mathrm{T}$ cell tolerance and regulates Th1- and Th17-cell differentiation. Immunity. 2007;26(5):579-591.

39. Pesu M, et al. T-cell-expressed proprotein convertase furin is essential for maintenance of peripheral immune tolerance. Nature. 2008;455(7210):246-250.

40. Gutcher I, Donkor MK, Ma Q, Rudensky AY, Flavell RA, Li MO. Autocrine transforming growth factor-beta1 promotes in vivo Th17 cell differentiation. Immunity. 2011;34(3):396-408.

41. Li MO, Flavell RA. TGF- $\beta$ : a master of all T cell trades. Cell. 2008;134(3):392-404.

42. Tran DQ. TGF- $\beta$ : the sword, the wand, and the shield of FOXP3(+) regulatory T cells. J Mol Cell Biol. 2012;4(1):29-37.

43. Wang R, Wan Q, Kozhaya L, Fujii H, Unutmaz D. Identification of a regulatory $\mathrm{T}$ cell specific cell surface molecule that mediates suppressive signals and induces Foxp3 expression. PLoS One. 2008;3(7):e2705

44. Wang R, Kozhaya L, Mercer F, Khaitan A, Fujii H, Unutmaz D. Expression of GARP selectively identifies activated human $\mathrm{FOXP}^{+}$ regulatory T cells. Proc Natl Acad Sci US A. 2009;106(32):13439-13444.

45. Wu S, Hong F, Gewirth D, Guo B, Liu B, Li Z. The molecular chaperone gp96/GRP94 interacts with Toll-like receptors and integrins via its C-terminal hydrophobic domain. J Biol Chem. 2012;287(9):6735-6742.

46. Acharya $\mathrm{M}$, et al. alphav Integrin expression by DCs is required for Th17 cell differentiation and development of experimental autoimmune encephalomyelitis in mice. J Clin Invest. 2010;120(12):4445-4452.

47. Aluwihare $\mathrm{P}$, et al. Mice that lack activity of $\alpha v \beta 6$ - and $\alpha v \beta 8$-integrins reproduce the abnormalities of Tgfb1- and Tgfb3-null mice. JCell Sci. 2009;122(pt 2):227-32.

48. Hartl FU, Bracher A, Hayer-Hartl M. Molecular chaperones in protein folding and proteostasis. Nature. 2011;475(7356):324-332.
49. Wolff S, Weissman JS, Dillin A. Differential scales of protein quality control. Cell. 2014;157(1):52-64.

50. Zhao R, et al. Navigating the chaperone network: an integrative map of physical and genetic interactions mediated by the hsp90 chaperone. Cell. 2005;120(5):715-727.

51. Taipale M, et al. Quantitative analysis of HSP90client interactions reveals principles of substrate recognition. Cell. 2012;150(5):987-1001.

52. Rohner N, et al. Cryptic variation in morphological evolution: HSP9O as a capacitor for loss of eyes in cavefish. Science. 2013;342(6164):1372-1375.

53. Whitesell L, Lindquist SL. HSP9O and the chaperoning of cancer. Nat Rev Cancer. 2005;5(10):761-772.

54. Randow F, Seed B. Endoplasmic reticulum chaperone gp96 is required for innate immunity but not cell viability. Nat Cell Biol. 2001;3(10):891-896.

55. Morales C, Wu S, Yang Y, Hao B, Li Z. Drosophila glycoprotein 93 Is an ortholog of mammalian heat shock protein gp96 (grp94, HSP90b1, HSPC4) and retains disulfide bond-independent chaperone function for TLRs and integrins. JImmunol. 2009;183(8):5121-5128

56. Pasare C, Medzhitov R. Toll pathway-dependent blockade of $\mathrm{CD} 4{ }^{+} \mathrm{CD} 25^{+} \mathrm{T}$ cell-mediated suppression by dendritic cells. Science. 2003;299(5609):1033-1036.

57. Dai J, Liu B, Li Z. Regulatory T cells and Toll-like receptors: what is the missing link? Int Immunopharmacol. 2009;9(5):528-533.

58. Gavin AL, et al. Adjuvant-enhanced antibody responses in the absence of toll-like receptor signaling. Science. 2006;314(5807):1936-1938.

59. Lammermann $\mathrm{T}$, et al. Rapid leukocyte migration by integrin-independent flowing and squeezing. Nature. 2008;453(7191):51-55.

60. Wang H, et al. TGF- $\beta$-dependent suppressive function of Tregs requires wild-type levels of CD18 in a mouse model of psoriasis. JClin Invest. 2008;118(7):2629-2639.

61. Edwards JP, Fujii H, Zhou AX, Creemers J, Unutmaz D, Shevach EM. Regulation of the expression of GARP/latent TGF- $\beta 1$ complexes on mouse $\mathrm{T}$ cells and their role in regulatory $\mathrm{T}$ cell and Th17 differentiation. J Immunol. 2013;190(11):5506-5515.

62. Akhurst RJ, Hata A. Targeting the TGFbeta signalling pathway in disease. Nat Rev Drug Discov. 2012;11(10):790-811.

63. Baker K, Raut P, Jass JR. Colorectal cancer cells express functional cell surface-bound TGF $\beta$. Int $J$ Cancer. 2008;122(8):1695-1700.

64. Ahn YO, Lee JC, Sung MW, Heo DS. Presence of membrane-bound TGF- $\beta 1$ and its regulation by IL-2-activated immune cell-derived IFN- $\gamma$ in head and neck squamous cell carcinoma cell lines. JImmunol. 2009;182(10):6114-6120.

65. Morales C, et al. Immune chaperone gp 96 drives the contributions of macrophages to inflammatory colon tumorigenesis. Cancer Res. 2014;74(2):446-459.

66. Hua Y, et al. Molecular chaperone gp 96 is a novel therapeutic target of multiple myeloma. Clin Cancer Res. 2013;19(22):6242-6251. 